\title{
Xenon difluoride in the organic laboratory: a tale of substrates, solvents and vessels
}

\author{
Christopher A. Ramsden \\ Lennard-Jones Laboratories, School of Physical and Geographical Sciences, \\ Keele University, Staffordshire ST5 5BG, UK \\ E-mail: c.a.ramsden@,keele.ac.uk
}

DOI: http://dx.doi.org/10.3998/ark.5550190.p008.436

\begin{abstract}
This Account summarises a series of studies of the reactions of xenon difluoride with organic substrates. It is concluded that xenon difluoride has two initial modes of reaction with organic substrates: single electron transfer (SET) and electrophilic addition. Reactions of aryltrimethylsilanes, carboxylic acids and esters, and trimethylsilyl enol ethers are discussed. The mode of reaction is determined by a combination of the solvent, the reaction vessel material and the presence of an acid catalyst. Pyrex, in the form of a flask surface, is a very effective catalyst for electrophilic reactions but this effect is inhibited by use of acetonitrile as solvent. Trimethylsilyl derivatives are particularly convenient substrates as these avoid the formation of $\mathrm{HF}$, which may catalyse side-reactions. Some studies using $\left[{ }^{18} \mathrm{~F}\right]-\mathrm{XeF}_{2}$ are described.
\end{abstract}

Keywords: Xenon difluoride, fluorination, hypervalent reagents, fluorodesilylation, rearrangement, fluorodecarboxylation, $\left[{ }^{18} \mathrm{~F}\right]-\mathrm{XeF}_{2}$.

\section{Table of Contents}

1. Introduction

2. $\mathrm{XeF}_{2}$ and 3-Centre, 4-Electron [3c-4e] Bonding

3. Reactions of $\mathrm{XeF}_{2}$ with Organic Substrates

3.1 Aryltrimethylsilanes

3.1.1 Fluorodesilylation

3.1.2 The influence of the vessel material

3.1.3 The influence of solvent

3.2 Carboxylic acids and esters

3.3 Trimethylsilyl enol ethers

4. $\left[{ }^{18} \mathrm{~F}\right] \mathrm{XeF}_{2}$ Studies 
5. Conclusions

Acknowledgements

References

\section{Introduction}

In 1992 we began an investigation of the reactions of trimethylsilylated organic substrates with xenon difluoride $\left(\mathrm{XeF}_{2}\right)$. There were several reasons for initiating this project.

(a) We had a longstanding interest in the chemistry of 1,3-dipoles, particularly heterocyclic mesomeric betaines, ${ }^{1-4}$ which in common with hypervalent reagents, such as $\mathrm{XeF}_{2}$ and $\mathrm{PhI}(\mathrm{OAc})_{2}$, are associated with 3 -centre, 4-electron [3c-4e] bonding. ${ }^{5}$ A common feature is a highest occupied molecular orbital (HOMO) that has the characteristics of a non-bonding molecular orbital (NBMO). We were therefore curious about similarities in behaviour between 1,3-dipoles and hypervalent reagents of the periodic table triad Te, I and Xe.,6

(b) Species with [3c-4e] bonding undergo ligand coupling [L-A-L $\left.\rightarrow \mathrm{L}_{2}+\mathrm{A}\right]$ and reactions of this type are potentially useful, especially if $\mathrm{A}$ is volatile, e.g., Xe, or recyclable, e.g., ArI.

(c) $\mathrm{XeF}_{2}$ is commercially available in reasonable quantities and is a stable, crystalline solid that is easy to handle. ${ }^{7,8}$ This makes it an attractive reagent for introducing fluorine into a molecule, especially at the end of a synthesis. In this context we were aware that late introduction of positron-emitting ${ }^{18} \mathrm{~F}\left(\mathrm{t}_{1 / 2} 110\right.$ minutes) into molecules using $\left[{ }^{18} \mathrm{~F}\right]-\mathrm{XeF}_{2}$ might be useful in Positron Emission Tomography (PET). ${ }^{9}$

(d) Reaction of $\mathrm{XeF}_{2}$ with trimethylsilyl derivatives can be expected to form volatile trimethylsilyl fluoride and gaseous xenon, potentially leading to clean reactions, with no HF formation, and facilitating workup.

(e) Introduction of fluorine into molecules often has an advantageous effect on biological properties and new fluorine methodology is therefore potentially useful.

Our studies had a lucky start and led to unexpected conclusions about the influence of reaction conditions on the reactions of $\mathrm{XeF}_{2}$ with organic substrates. The purpose of this Account is to give an overview of our work in the area.

\section{2. $\mathrm{XeF}_{2}$ and 3-Centre, 4-Electron [3c-4e] Bonding}

Molecules associated with [3c-4e] bonds cannot be fully represented by conventional 2-centre, 2electron [2c-2e] covalent bonds and are usually represented by dipolar or hypervalent structures. Examples commonly encountered in organic chemistry are 1,3-dipoles and hypervalent reagents of Group 15-18 elements. 1,3-Dipoles are usually represented by dipolar structures of the general 
type 1b and 1c but sometimes, especially for sulfur derivatives, hypervalent structures of the general type 1a are used (e.g., $\mathrm{SO}_{2}$ ). Examples include the azomethine ylides $3{ }^{10}$ the pyridinium3-olate $4,{ }^{2,11}$ and the thieno[3,4-c]thiophene 5. ${ }^{3,12}$ It is seldom useful to use the linear polar resonance hybrids $\mathbf{2 b}$ and $\mathbf{2 c}$ to represent 'hypervalent' molecules and these are represented by linear structures of the general type 2a. Examples include many iodine reagents, ${ }^{13}$ including (diacetoxyiodo)benzene 6, the Dess-Martin periodinane 7, and derivatives of xenon, ${ }^{14}$ including $\mathrm{XeF}_{2}$ 8. Dipolar resonance hybrids of these reagents, e.g., 8a, do emphasise the polar nature of these hypervalent bonds and the high electrophilic reactivity associated with them.

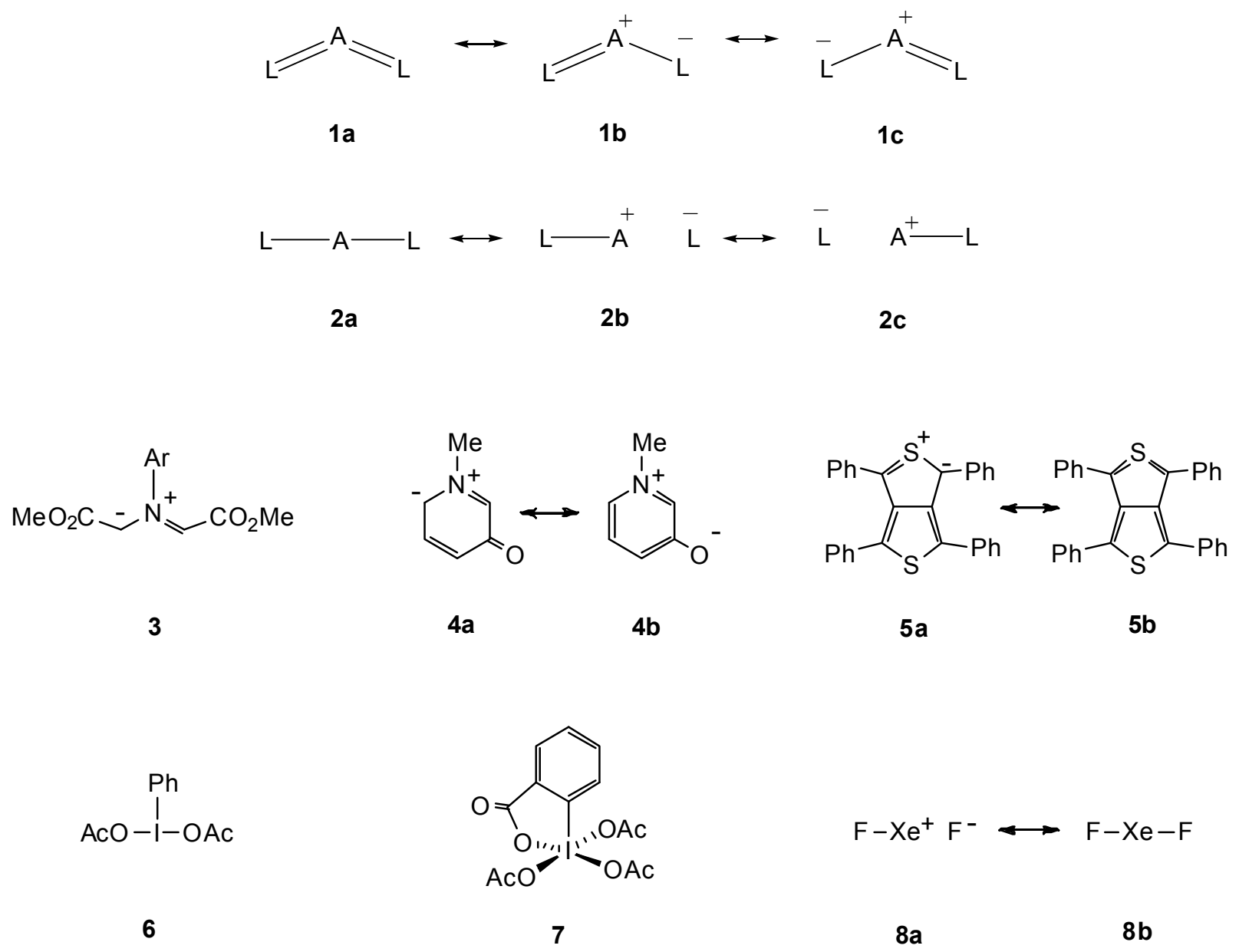

Common features of the molecules 3-8 are the three-centre bonds which when localised lead to a highest occupied molecular orbital (HOMO) that has the characteristics of non-bonding molecular orbital (NBMO) with a node on the central atom (Figure 1). For stability both general types 1 and 2 require that the ligands $\mathrm{L}$ are electronegative and more electronegative than the central atom A. Thus the nitro group $\left(\mathrm{R}-\mathrm{NO}_{2}\right)$ is stable but sulfur analogues $\left(\mathrm{R}-\mathrm{NS} \mathrm{S}_{2}\right)$ are unknown. Similarly, fluorine and chlorine form hypervalent derivatives of iodine (e.g., $\mathrm{PhIF}_{2}$ and $\mathrm{PhICl}_{2}$ ) but bromine is not electronegative enough to form $\mathrm{PhIBr}_{2}$. 


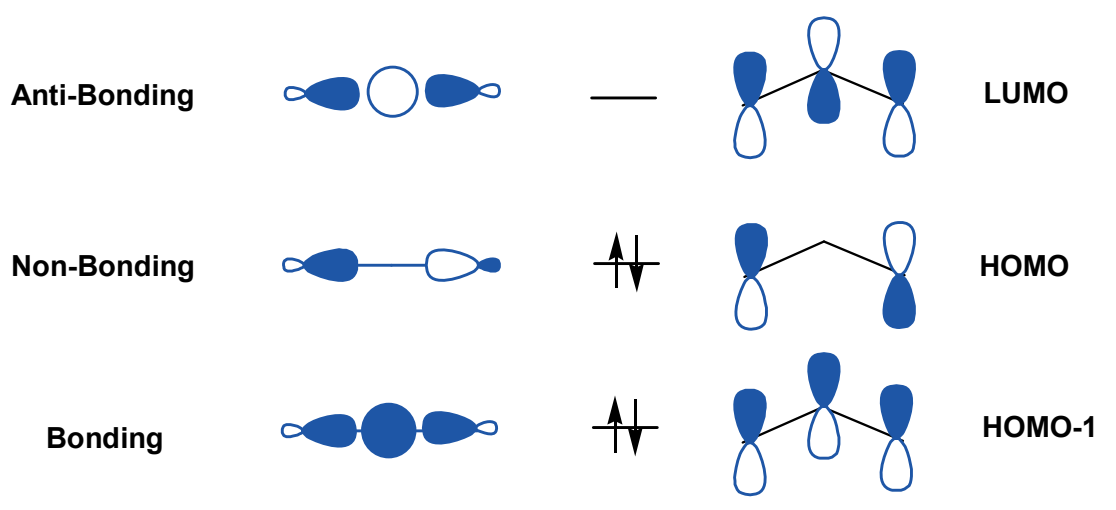

Figure 1. A comparison of the frontier orbitals of hypervalent molecules and 1,3-dipoles.

The orbital energy and overlap requirements for [3c-4e] bonding results in HOMOs that are relatively high in energy and, depending on the ligands, LUMOs that are relatively low in energy. These bonding features lead to useful modes of reaction that are common to both types of species. These include ligand coupling, syn-addition and one-electron oxidation. ${ }^{5}$ Frontier orbital analysis has been a powerful tool for understanding the reactivity and selectivity of 1,3dipolar cycloadditions and in many cases the outcome can be understood in terms of a HOMO that has the features of a NBMO. At the outset of our work with $\mathrm{XeF}_{2}$ we were interested in potential ways in which the NBMO of hypervalent species might influence their reactivity and one possibility, discussed in the next section, was the starting point of our studies.

\section{Reactions of $\mathrm{XeF}_{2}$ with Organic Substrates}

\subsection{Aryltrimethylsilanes}

3.1.1 Fluorodesilylation. We were aware that a hypervalent derivative of iodine, [hydroxy(tosyloxy)iodo]benzene 9 (Koser's reagent), reacts with aryltrimethylsilanes 10 to give diaryliodonium tosylates 11 (Equation 1). ${ }^{15}$ On the assumption that hypervalent iodine and hypervalent xenon might have properties in common, we wondered if $\mathrm{XeF}_{2}$ might similarly react with aryltrimethylsilanes $\mathbf{1 0}$ to give arylxenon fluorides $\mathbf{1 2}$ followed by ligand coupling to give aryl fluorides (Equation 2). Mechanistically this seemed reasonable on the assumption that electrophilic addition of $\mathrm{XeF}_{2}$ to aryltrimethylsilanes might lead to the intermediate cations $\mathbf{1 3}$ in which the $\pi$ system of the cation is stabilised by the NBMO of the hypervalent xenon and by the $\beta$ effect of the trimethylsilyl substituent. Subsequent fluorodesilylation could then lead to the intermediate 14 (Equation 3). A number of aryl xenon species of the type Ar-Xe-F and Ar-XeOCOR have been isolated and characterised, and ligand coupling with elimination of xenon has been demonstrated. ${ }^{16-21}$ 


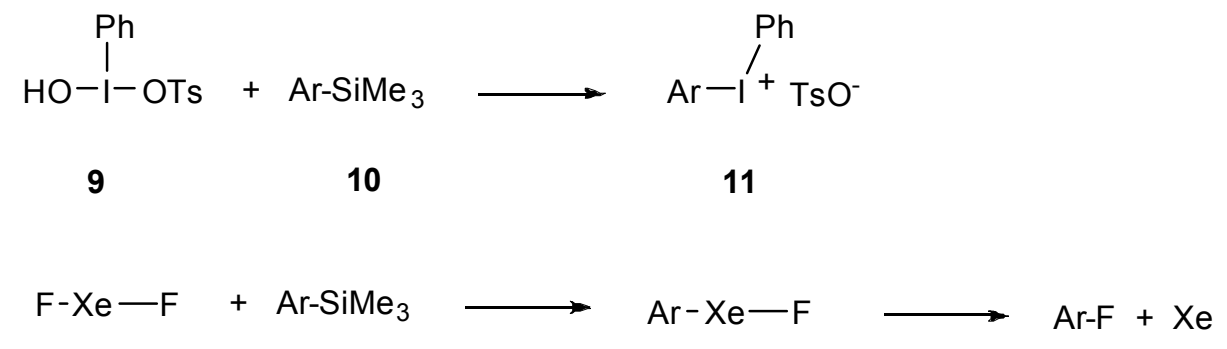

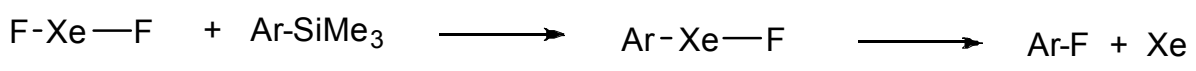

10

12

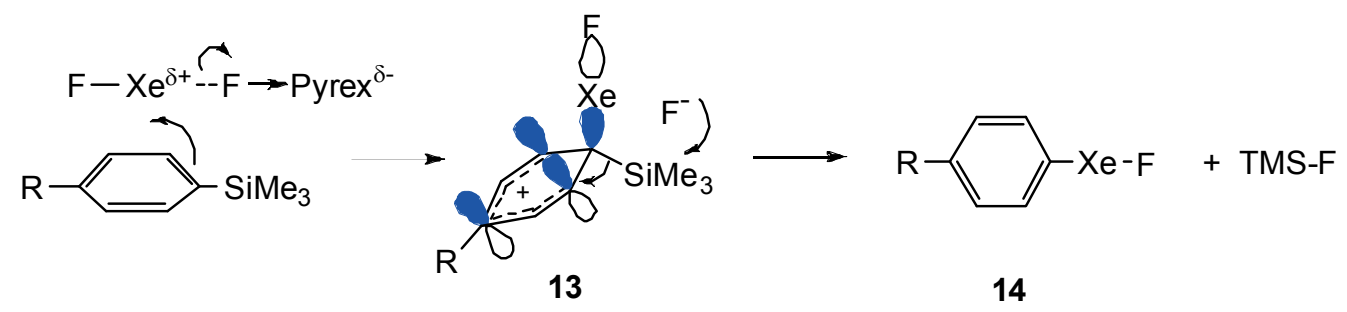

With these mechanistic possibilities in mind, we investigated the reaction of $\mathrm{XeF}_{2}$ with 4-tbutylphenyltrimethylsilane $10\left(\mathrm{Ar}=4-\mathrm{Bu}^{t} \mathrm{C}_{6} \mathrm{H}_{4}\right)$. Our initial work with $\mathrm{XeF}_{2}$ was carried out in a glovebox under a dry, inert atmosphere but we subsequently found that this was unnecessary. However, our selection of conditions for our first $\mathrm{XeF}_{2}$ reaction turned out to be extremely fortuitous and vital for success. We used a conventional Pyrex flask with $\mathrm{C}_{6} \mathrm{~F}_{6}$ as solvent and two equivalents of $\mathrm{XeF}_{2}$. At room temperature under these conditions an almost quantitative yield of 1-t-butyl-4-fluorobenzene $14\left(\mathrm{R}=\mathrm{Bu}^{\mathrm{t}}\right)$ was rapidly obtained. ${ }^{22}$ Figure 2 a shows the original ${ }^{1} \mathrm{H}$ NMR spectrum of the reaction mixture, including the doublet attributable to TMS-F. Similar behaviour was observed using 4-chlorophenyltrimethylsilane $\mathbf{1 0}\left(\mathrm{Ar}=4-\mathrm{ClC}_{6} \mathrm{H}_{4}\right)$ (Figure 2b). When the aryl ring carried an electron-withdrawing substituent, e.g., $\mathrm{NO}_{2}, \mathrm{COMe}$, yields were lower, which is consistent with an electrophilic-substitution mechanism. ${ }^{23}$

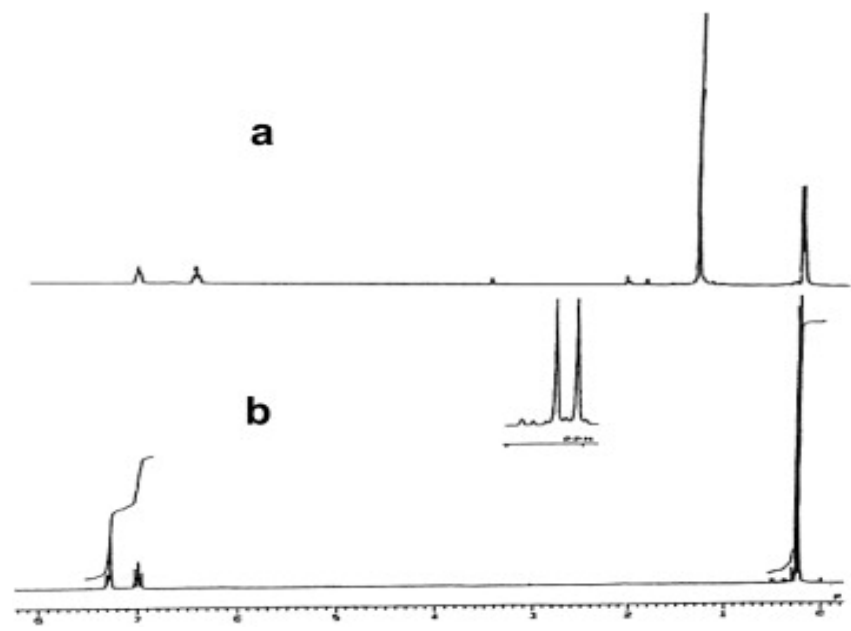

Figure 2. ${ }^{1} \mathrm{H}$ NMR of reaction mixtures showing quantitative formation of (a) 1-tert-butyl4-fluorobenzene and (b) 1-chloro-4-fluorobenzene together with trimethylsilyl fluoride. ${ }^{24}$ 
3.1.2 The influence of the vessel material. When we attempted to carry out the fluorodesilylation reactions (Equation 2) in a PTFE flask no reaction was observed. In a series of experiments using 4-tolyltrimethylsilane $\mathbf{1 0}\left(\mathrm{Ar}=4-\mathrm{MeC}_{6} \mathrm{H}_{4}\right)$ and two equivalents of $\mathrm{XeF}_{2}$ in $\mathrm{C}_{6} \mathrm{~F}_{6}$ in reaction flasks made of PTFE, quartz or soda glass no reaction was observed. However, in a Pyrex flask a $\sim 70 \%$ yield of 4-fluorotoluene was obtained. When the Pyrex flask was pre-washed with $2 \mathrm{M}$ $\mathrm{NaOH}$, rinsed with acetone and dried, there was no reaction of the silane substrate but the flask could be reactivated by washing with chromic acid. We concluded from these studies that the Pyrex surface acts as a heterogeneous acid catalyst. ${ }^{23,25}$

Pyrex is a borosilicate glass containing $\sim 13 \% \mathrm{~B}_{2} \mathrm{O}_{3}$ and $\sim 2 \% \mathrm{Al}_{2} \mathrm{O}_{3}$ and we propose that $\mathrm{XeF}_{2}$ can bind to the Lewis acid sites residing in the Pyrex surface to give a polarised form $\left[\mathrm{FXe}^{\delta+}---\mathrm{F} \rightarrow \mathrm{Pyrex}^{\delta-}\right]$ that can act as an electrophilic agent leading to the intermediate $\mathbf{1 3}$ as shown in Equation 3. In our earlier studies our enthusiasm for making direct comparisons with hypervalent iodine chemistry led us to suggest that electrophilic reactions occur by reaction with $\mathrm{FXe}^{+}\left(\mathrm{cf}\left(\mathrm{Ar}_{2} \mathrm{I}^{+}\right)\right.$. However, $\mathrm{FXe}^{+}$is far too unstable to be formed under these reaction conditions and it is more reasonable to propose that it reacts as an $\mathrm{FXe}^{+}$equivalent, as for instance, in $\mathrm{FXe}^{\delta+}--\mathrm{F} \rightarrow$ Pyrex $^{\delta-}$.

3.1.3 The influence of solvent. We established that freon $\left(\mathrm{CFCl}_{3}\right)$ is an alternative solvent to $\mathrm{C}_{6} \mathrm{~F}_{6}$ but when acetonitrile was used as solvent aryl fluoride formation (Equation 2) did not take place for a range of substrates 10 (yields 0-4\%). Acetonitrile is a weak base and we assume that it blocks the Lewis acid sites on the Pyrex surface $[\mathrm{MeCN} \rightarrow$ Pyrex] preventing activation of the $\mathrm{XeF}_{2}$, as shown in Equation 3.

These observations prompted us to make a ${ }^{19} \mathrm{~F}$ NMR study of the stability of $\mathrm{XeF}_{2}$ in $\mathrm{C}_{6} \mathrm{~F}_{6}$, $\mathrm{CFCl}_{3}, \mathrm{MeCN}_{,} \mathrm{CHCl}_{3}, \mathrm{CH}_{2} \mathrm{Cl}_{2}$ and $\mathrm{H}_{2} \mathrm{O}$ solution, and in the corresponding deuterated solvents. These studies were carried out using nmr tubes made of Pyrex or quartz, or lined with PTFEFEP. Table 1 shows the observed half-lives $\left(t_{1 / 2}\right)$ and lifetimes $\left(t_{1}\right)$ of $\mathrm{XeF}_{2}$ in the various vesselsolvent combinations. ${ }^{25}$

Table 1. Approximate half-lives $\left(t_{1} / 2\right)$ and lifetimes $\left(t_{1}\right)$ of $\mathrm{XeF}_{2}$ in vessel/solvent systems ${ }^{26}$

\begin{tabular}{ccccccc}
\hline Solvent & \multicolumn{2}{c}{ PTFE-FEP } & \multicolumn{2}{c}{ Pyrex } & \multicolumn{2}{c}{ Quartz } \\
\hline $\mathrm{t}_{1 / 2}$ & $\mathrm{t}_{1}$ & $\mathrm{t}_{1 / 2}$ & $\mathrm{t}_{1}$ & $\mathrm{t}_{1 / 2}$ & $\mathrm{t}_{1}$ \\
$\mathrm{CH}_{2} \mathrm{Cl}_{2}$ & $>7$ days & $\gg 7$ days & $0.6 \mathrm{~h}$ & $2 \mathrm{~h}$ & $2.5 \mathrm{~h}$ & $4 \mathrm{~h}$ \\
$\mathrm{CHCl}_{3}$ & $\sim 4$ days & 6 days & $0.25 \mathrm{~h}$ & $0.6 \mathrm{~h}$ & $2.5 \mathrm{~h}$ & $4 \mathrm{~h}$ \\
$\mathrm{CFCl}_{3}$ & $>7$ days & $\gg 7$ days & $1 \mathrm{~h}$ & $2.5 \mathrm{~h}$ & $1.5 \mathrm{~h}$ & $3 \mathrm{~h}$ \\
$\mathrm{CH}_{3} \mathrm{CN}$ & $>7$ days & $\gg 7$ days & $48 \mathrm{~h}$ & $72 \mathrm{~h}$ & $>168 \mathrm{~h}$ & $\gg 168 \mathrm{~h}$ \\
$\mathrm{H}_{2} \mathrm{O}$ & $<1 \mathrm{~h}$ & $<24 \mathrm{~h}$ & $2 \mathrm{~h}$ & $7 \mathrm{~h}$ & $1.5 \mathrm{~h}$ & $4 \mathrm{~h}$ \\
$\mathrm{C}_{6} \mathrm{~F}_{6}$ & $>7$ days & $>7$ days & $4 \mathrm{~h}$ & $10 \mathrm{~h}$ & - & - \\
\hline
\end{tabular}

With the exception of $\mathrm{H}_{2} \mathrm{O}$ as solvent, $\mathrm{XeF}_{2}$ has good stability in PTFE-FEP with half-lives of several days in all the solvents studied (Table 1). In contrast, solutions in Pyrex tubes have half-lives of hours, with the interesting exception of $\mathrm{MeCN}$ as solvent in which the half-life is 
two days. Lifetimes in quartz tend to be slightly longer than in Pyrex. Fluoride formation was detected in both Pyrex and quartz tubes and this appears to result from reduction of $\mathrm{XeF}_{2}$ on the surface $\left[\mathrm{XeF}_{2}+2 \mathrm{e}^{-} \rightarrow \mathrm{Xe}+2 \mathrm{~F}^{-}\right]$. This competing surface reaction limits the lifetime of the $\mathrm{XeF}_{2}$ in Pyrex (and quartz) and explains the optimal use of two equivalents of $\mathrm{XeF}_{2}$ for fluorodesilylation (Equation 2).

It is also clear that $\mathrm{XeF}_{2}$ reacts directly with some solvents and this is particularly noticeable for chloroform which is best avoided as a solvent. In both PTFE-FEP and Pyrex the lifetimes in $\mathrm{CHCl}_{3}$ are significantly shorter than in the other organic solvents. We made a separate study of the decomposition of $\mathrm{XeF}_{2}$ in $\mathrm{CHCl}_{3}$ and have suggested mechanisms that may explain some of the byproducts formed, including $4-\mathrm{Bu}^{\mathrm{t}}-\mathrm{C}_{6} \mathrm{H}_{4}-\mathrm{CCl}_{3}$ when fluorodesilylation of (4-Bu ${ }^{\mathrm{t}}$-phenyl)trimethylsilane is carried out in $\mathrm{CHCl}_{3}{ }^{27}$

As a result of the studies summarised in Table 1, we can note that $\mathrm{XeF}_{2}$ is less reactive towards $\mathrm{CH}_{2} \mathrm{Cl}_{2}$ than to $\mathrm{CHCl}_{3}$ and that the half-life in $\mathrm{CH}_{2} \mathrm{Cl}_{2}$ is significantly longer than in $\mathrm{CHCl}_{3}$. It seemed that for rapid reactions $(\leq 1 \mathrm{~h})$, such as fluorodesilylation, $\mathrm{CH}_{2} \mathrm{Cl}_{2}$ might be a convenient alternative solvent. We were aware that Bardin and Frohn had investigated the fluorodesilylation of 4-fluorophenyltrimethylsilane 15 in an FEP flask using $\mathrm{CH}_{2} \mathrm{Cl}_{2}$ as solvent and $\mathrm{BF}_{3} \cdot \mathrm{OEt}_{2}$ as a homogeneous Lewis acid catalyst. This led to a complex mixture including a $34 \%$ yield of 1,4-difluorobenzene (Scheme 1). ${ }^{28}$ When we reacted the same substrate with two equivalents of $\mathrm{XeF}_{2}$ in $\mathrm{CH}_{2} \mathrm{Cl}_{2}$ solution in a Pyrex flask, a GC-MS analysis of the crude reaction mixture after one hour showed almost quantitative formation of 1,4-difluorobenzene. Figure $3 \mathrm{~b}$ shows the ${ }^{1} \mathrm{H}$ NMR of a reaction mixture in $\mathrm{CD}_{2} \mathrm{Cl}_{2}$ when the reaction was almost complete, together with spectra of authentic reactant (Figure 3a) and product (Figure 3c). This result led to the conclusions that (i) Pyrex in the form of a large surface area is a very effective catalyst for fluorodesilylation by $\mathrm{XeF}_{2}$ and (ii) $\mathrm{CH}_{2} \mathrm{Cl}_{2}$ is a convenient solvent for fast electrophilic reactions of $\mathrm{XeF}_{2}$. In the following sections it will be seen that $\mathrm{XeF}_{2}$ can react by an alternative mechanism and for these reactions a different solvent may be appropriate.

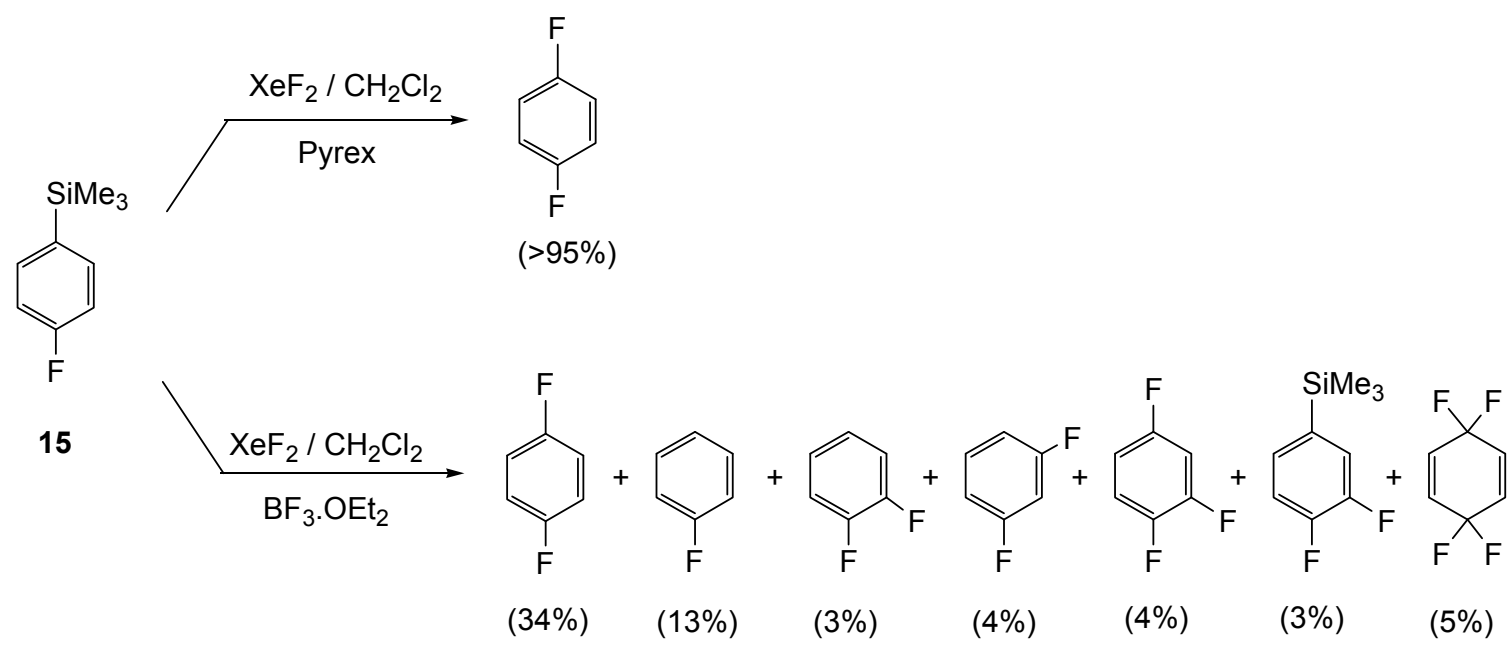

\section{Scheme 1}


It is interesting to note that $\mathrm{XeF}_{2}$ in water has similar lifetimes in both PTFE-FEP and Pyrex (Table 1). Our work with $\mathrm{XeF}_{2}$ has always used dry solvents, and initially a dry atmosphere in a glovebox, but it is questionable whether this is necessary. When we tried fluorodesilylation reactions in wet $\mathrm{CH}_{2} \mathrm{Cl}_{2}$ in a limited study no adverse effects on the outcome of the reactions were observed. However, it should be noted that a trace of alkali in water leads to rapid decomposition of $\mathrm{XeF}_{2}$.

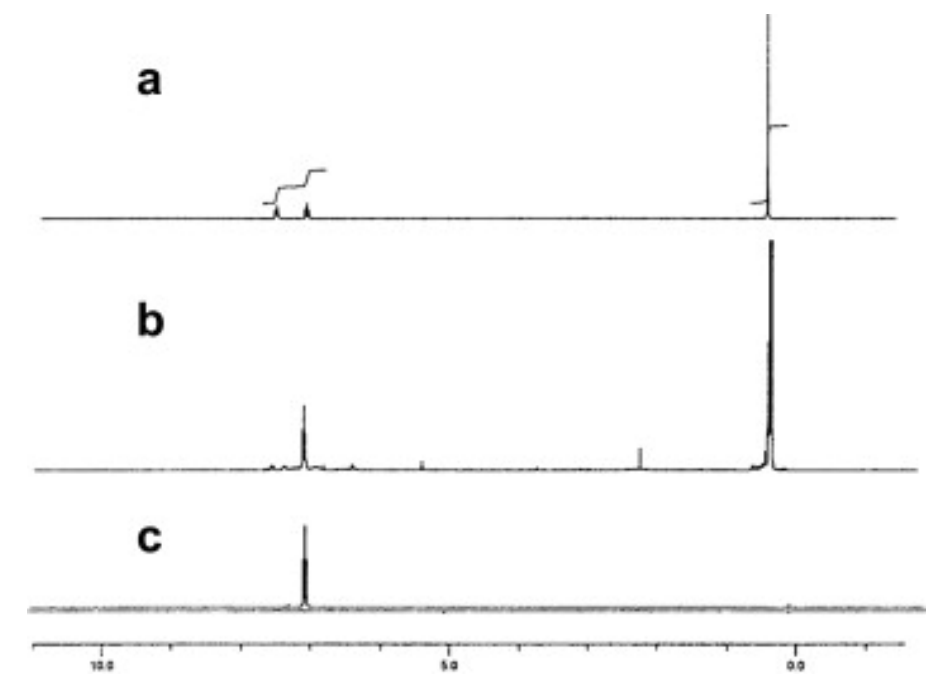

Figure 3. ${ }^{1} \mathrm{H}$ NMR of (a) 4-fluorophenyltrimethylsilane, (b) reaction mixture after treatment of 4-fluorophenyltrimethylsilane with $\mathrm{XeF}_{2}$ in $\mathrm{CD}_{2} \mathrm{Cl}_{2}$ at room temperature and (c) authentic 1,4difluorobenzene. ${ }^{24}$

\subsection{Carboxylic acids and esters}

Our work with aryltrimethylsilanes (Section 3.1) led us to extend our investigations to trimethylsilyl benzoates $\mathbf{1 7}$ in anticipation that a decarboxylation sequence might provide an alternative route to aryl fluorides. In fact we observed different modes of reaction depending upon the solvent used. Although these studies on the benzoates were carried out before we recognised the catalytic effect of the Pyrex flask, we subsequently rationalised the results in terms of Pyrex/solvent effects.

The reaction of trimethylsilyl benzoates 17 with $\mathrm{XeF}_{2}$ were not as clean as those with arylsilanes 10, but certain products predominated depending upon the solvent or aryl group. In Pyrex flasks using $\mathrm{CH}_{2} \mathrm{Cl}_{2}$ or $\mathrm{C}_{6} \mathrm{~F}_{6}$ as solvent, fluoroformate 19 formation was observed. ${ }^{29}$ This can be rationalised by electrophilic addition of activated $\mathrm{XeF}_{2}\left[\mathrm{FXe}^{\delta+}---\mathrm{F} \rightarrow\right.$ Pyrex $\left.^{\delta-}\right]$ (cf. Equation 3) leading to the fluoroxenon esters 18 which under the reaction conditions, possibly with Pyrex catalysis, results in aryl migration accompanied by fluoride addition and elimination of xenon (Scheme 2). The fluoroformates 19 are accompanied by some aroyl fluoride (ArCOF) and a GCMS analysis of the reaction mixtures indicated smaller amount of solvent-derived products, probably arising from radical intermediates. 

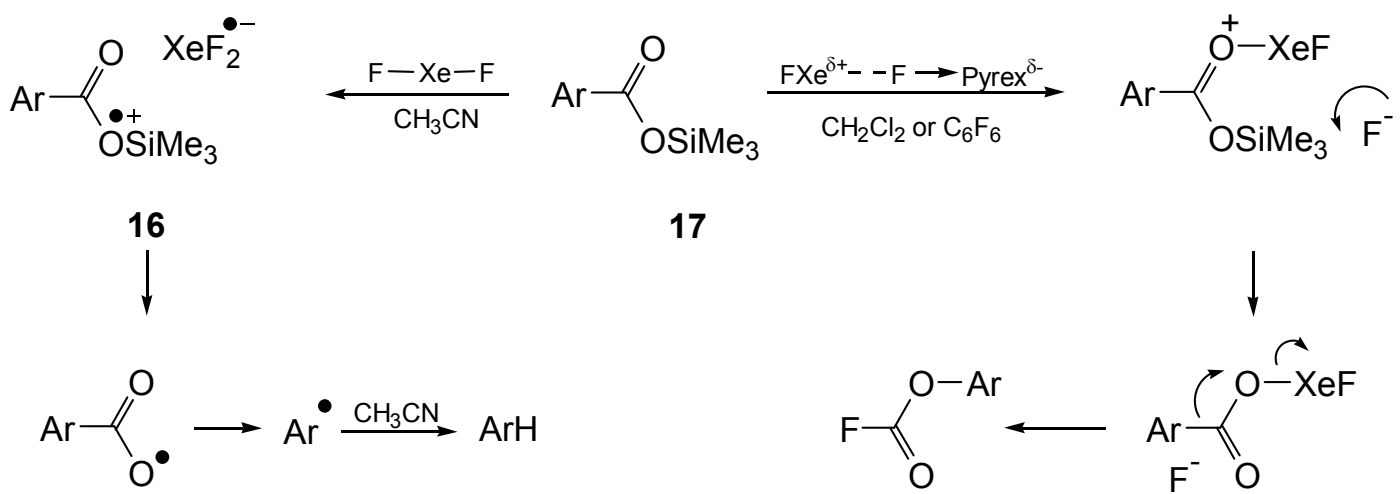

17

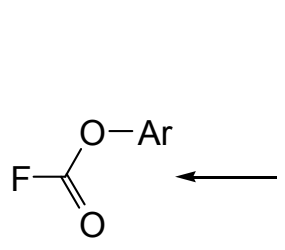

19

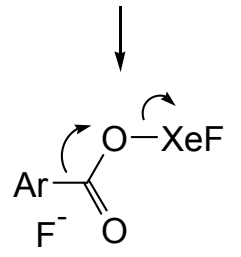

18

\section{Scheme 2}

In acetonitrile solution a different mode of reaction of $\mathrm{XeF}_{2}$ is observed. No rearrangement reactions were detected and the predominant products were the corresponding arenes (Ar-H). Under these conditions, where the weak base $\mathrm{MeCN}$ inhibits Pyrex catalysis, unionised $\mathrm{XeF}_{2}$ appears to react by single-electron transfer mechanism (SET) (cf nitro group chemistry). Formation of the radical ion pairs $\mathbf{1 6}$ and subsequent fluorodesilylation and decarboxylation leads to aryl radicals which in acetonitrile solution give the arene products (Scheme 2). ${ }^{29}$

Because carboxylic acids are more accessible than their trimethylsilyl esters we broadened the scope of our studies by investigating a series of structurally selected acids under both Pyrexcatalysed and non-catalysed conditions. ${ }^{30}$ In a series of detailed studies Patrick and co-workers had previously shown that reaction of carboxylic acids with $\mathrm{XeF}_{2}$ in $\mathrm{CH}_{2} \mathrm{Cl}_{2}$ solution in polyethylene flasks gave fluorides $\left[\mathrm{RCO}_{2} \mathrm{H} \rightarrow \mathrm{RF}\right] .{ }^{31-33}$ We therefore undertook a comparison of the reactions of carboxylic acids with $\mathrm{XeF}_{2}$ in (i) $\mathrm{CH}_{2} \mathrm{Cl}_{2} / \mathrm{PTFE}$ and (ii) $\mathrm{CH}_{2} \mathrm{Cl}_{2} / \mathrm{Pyrex}^{30}$ Results of these studies are summarised in Table 2. In accord with the results of Patrick and co-workers, reaction of the acids 20-25 in $\mathrm{CH}_{2} \mathrm{Cl}_{2}$ /PTFE gives predominantly fluorides (26-31, Table 2). Fluoride formation is rationalised in terms of a SET mechanism leading to fluorination of an aryl/alkyl radical within the solvent shell (Scheme 3). In contrast to MeCN (Scheme 2) participation of $\mathrm{CH}_{2} \mathrm{Cl}_{2}$ in these reactions is minor.

Reaction of carboxylic acids $\left(\mathrm{RCO}_{2} \mathrm{H}\right)$ with $\mathrm{XeF}_{2}$ in $\mathrm{CH}_{2} \mathrm{Cl}_{2} / \mathrm{Pyrex}$ results in quite different product profiles. The main products can all be rationalised in terms of the initial formation of a fluoroxenon ester $\mathbf{4 2}$ and the subsequent course of reaction is then determined by the nature of the substituent $\mathrm{R}$ (Table 2). Scheme 3 summarises the alternative pathways that rationalise the results obtained using a diverse set of acids.

When the substituent $\mathrm{R}$ is a good migrating group such as adamant-1-yl (e.g. 20) rearrangement to the fluoroformate (cf Scheme 2) followed by ester cleavage gives an alcohol (e.g. 32)(pathway a, Scheme 3). Alternatively, decarboxylation and cation formation can occur (pathway b). Diphenylacetic acid 21 forms the ether $\mathbf{3 3}$ in high yield which appears to be formed by partial rearrangement and trapping of the resulting diphenylmethanol (pathway a) by the 
secondary cation (pathway b). For dicyclohexylacetic acid 22 only deprotonation products (34 and 35), formed via an intermediate secondary cation, are observed (pathway b). The benzylic acid 23 gives mainly the ester 36, presumably formed via trapping the relatively stable benzyl cation (pathway b), but a small amount of dibenzyl ether (pathway $a+b$ ) was also detected.

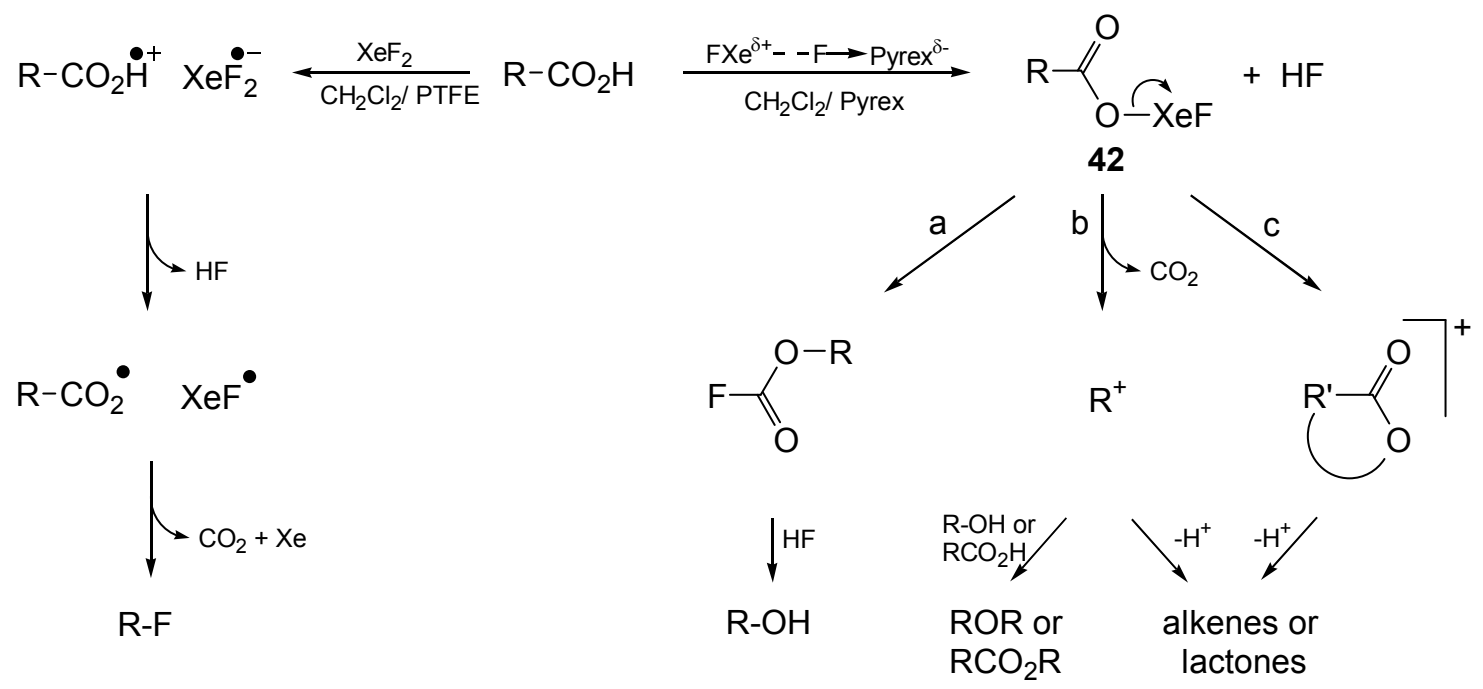

\section{Scheme 3}

An interesting variation occurs when the alkyl chain is extended. Reaction of 4phenylbutanoic acid 24 gave, in addition to the ester 39, the cyclisation products 37 and 38 (Table 2, entry 5). The formations of these cyclic products (pathway c) can be rationalised by the competing cyclisations of the fluoroxenon ester 43 (Scheme 4), which avoid formation of the unstable primary carbenium ion.

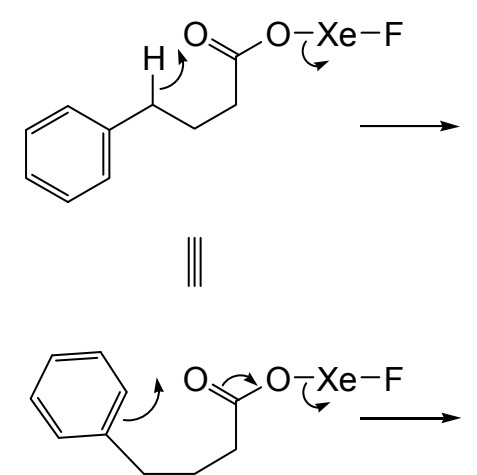

43<smiles>O=C1CC[C+](c2ccccc2)CO1</smiles>
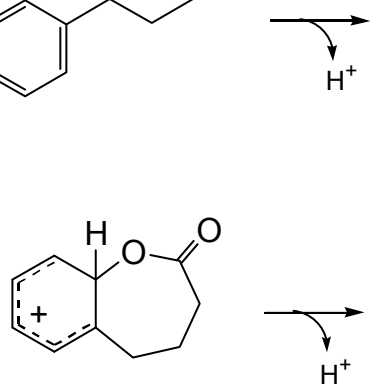

\section{Scheme 4}

Styrylacetic acid 25 gave a modest yield of the ester $\mathbf{4 1}$ but mainly the lactone 40, probably formed by initial reaction of $\mathrm{XeF}_{2}$ with the double bond and subsequent cyclisation of the benzyl cation. 
Table 2. Products of reaction of $\mathrm{XeF}_{2}$ with carboxylic acids 20-25 ${ }^{30}$

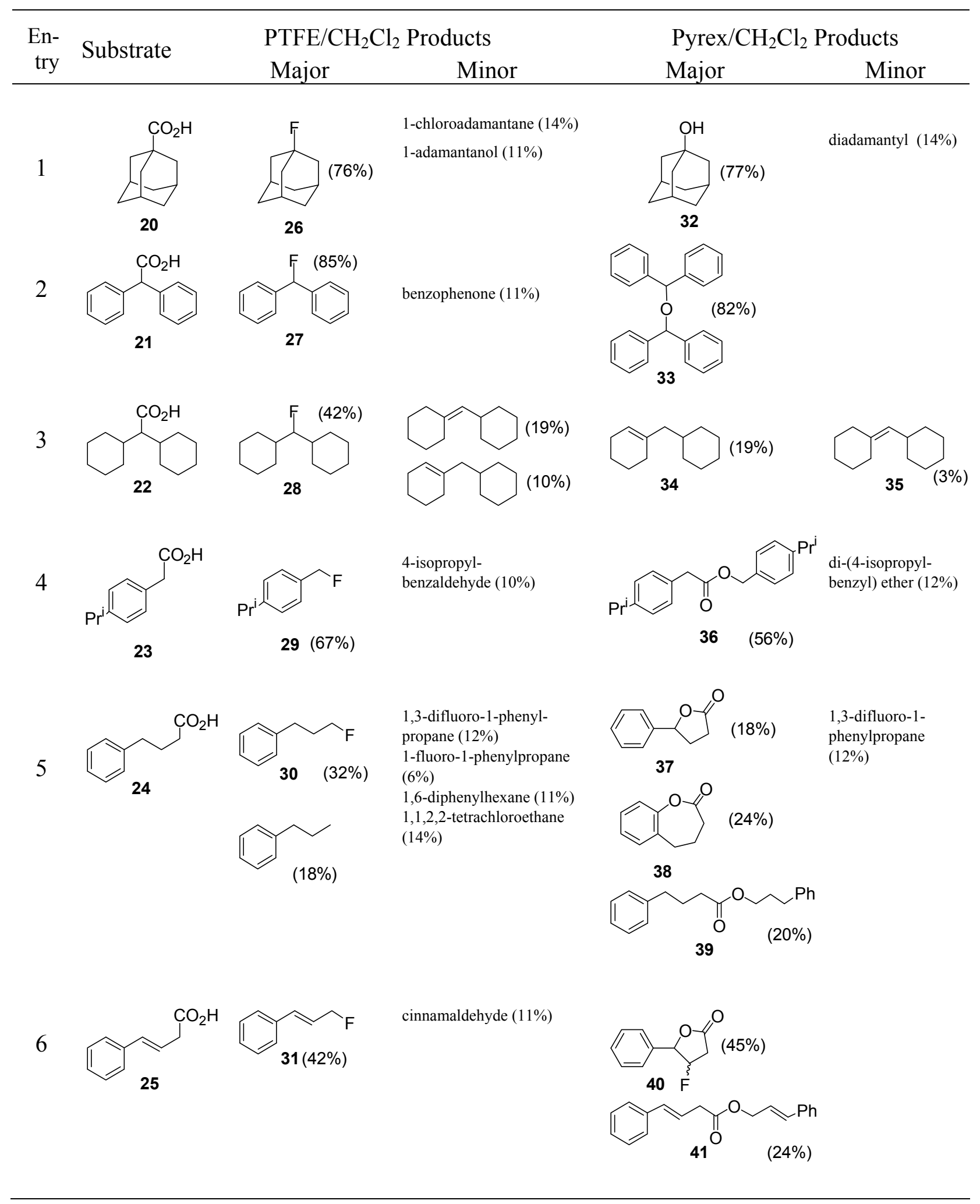




\subsection{Trimethylsilyl enol ethers}

A third class of derivatives that attracted our attention was trimethylsilyl enol ethers (e.g., 4447). Here we found the use of Pyrex with $\mathrm{CFCl}_{3}$ or $\mathrm{C}_{6} \mathrm{~F}_{6}$ solutions gave complex results but use of Pyrex and $\mathrm{MeCN}$ solution resulted in interesting trends. ${ }^{34}$<smiles>COC1=CCCCC1</smiles>

44<smiles>[R]C(=C)O[Na]</smiles>

45<smiles>COC1=Cc2ccccc2CC1</smiles>

46

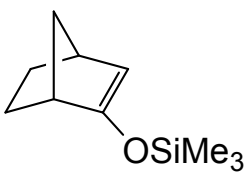

47

Cyclic ethers (e.g., $\mathbf{4 4}, \mathrm{n}=1,2$ ) give high yields of the $\alpha$-fluoroketones but acyclic derivatives (e.g., $45, \mathrm{R}=\mathrm{Ph}, \mathrm{Bu}^{t}$ ) give a mixture of the ketone and the $\alpha$-fluoroketone. Mechanistically we have interpreted this as an initial SET to unpolarised $\mathrm{XeF}_{2}$ to give the radical ion pairs 48 (Scheme 5). For cyclic enols 44 , where the radical centre is secondary $\left(48, R^{2}=\right.$ alkyl), fluorination by the radical anion or its products occurs giving after fluorodesilylation the fluoroketone 49. In the case of the acyclic enol ethers $\mathbf{4 5}$ where the initial cation has a primary radical centre $\left(\mathbf{4 8}, \mathrm{R}^{2}=\mathrm{H}\right)$, intramolecular 1,5-hydrogen transfer occurs leading to the ketone $\mathbf{5 0}$ in addition to the fluoroketone 49 (Scheme 5). Using $\mathrm{CD}_{3} \mathrm{CN}$ as solvent, no deuterium incorporation into the ketone product was observed, supporting the intramolecular mechanism.

Interesting variations were observed using the tetralone enol ether $\mathbf{4 6}$ and the norcamphor derivative 47, which both gave products derived from the solvent $(\mathrm{MeCN})$, in addition to the products 49 and 50 (Scheme 5). In contrast to $\alpha$-tetralone trimethylsilyl enol ether which gave mainly the $\alpha$-fluoroketone $(90 \%)$, the $\beta$-tetralone derivative $\mathbf{4 6}$ gave the tricyclic oxazole derivatives $58(34 \%)$ in addition to fluoroketone (14\%) and ketone (52\%). We attribute this

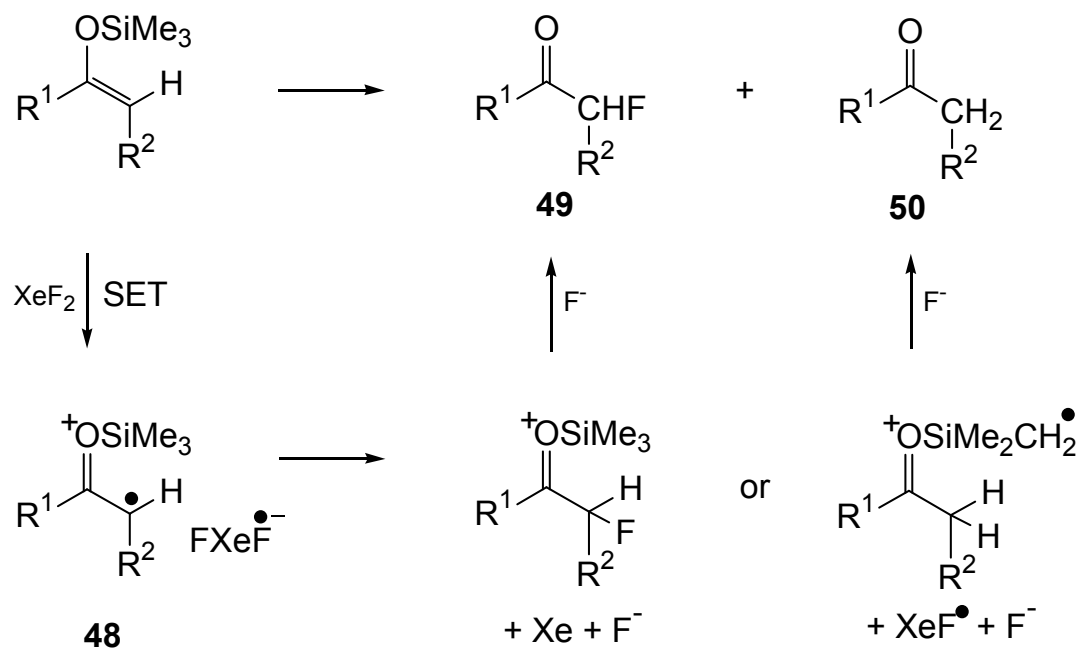

\section{Scheme 5}


<smiles>C[C+](C)C1CCCc2ccccc21</smiles><smiles>O=C1CCCc2ccccc21</smiles>

55

$$
\begin{aligned}
& \text { No solvent- } \\
& \text { derived products }
\end{aligned}
$$<smiles>C[14CH2][C@@H]1[CH]c2ccccc2CC1</smiles>

52

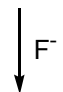<smiles></smiles>

56<smiles>CC1=N[In]([Y](C)(C)C)C2c3ccccc3C=CC2O1</smiles>

58

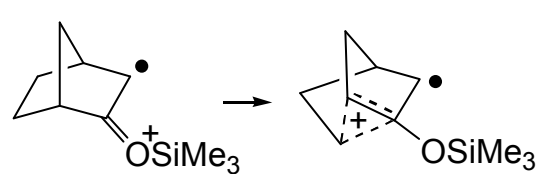

53<smiles>[3H][I-]C</smiles>

54<smiles>C[C@H]1C(=O)[C@H]2CC[C@@H]1C2</smiles>

57<smiles>CNC1CCCC1</smiles><smiles>CC(=O)NC1C(=O)C2CCC1C2</smiles>

59

\section{Scheme 6}

difference in behaviour of the two tetralone derivatives to the relative stabilities of the isomeric radical cations $\mathbf{5 1}$ and $\mathbf{5 2}$. The conjugated radical ion $\mathbf{5 2}$ is more stable than the cross-conjugated radical ion $\mathbf{5 1}$. The more reactive system $\mathbf{5 1}$ is readily fluorinated $(90 \%)$ within the solvent shell and competing formation of the radical $\mathbf{5 5}$ does not occur. In the case of the more stable system 52 the fluorinating agent diffuses away and hydrogen transfer predominates; however, some fluorodesilylation competes giving the reactive radical 56 which rapidly gives the solvent derived oxazoles 58 (Scheme 6). Similar behaviour is observed for the enol ether of norcamphor 53 which gives the solvent-derived amide 59 as the major product (58\%). This result led us to suggest that the radical cation $\mathbf{5 3}$ also has enhanced stability, possibly due to a non-classical structure 54 which desilylates to the reactive radical 57.

\section{4. $\left[{ }^{18} \mathrm{~F}\right] \mathrm{XeF}$ Studies}

Positron Emission Tomography (PET) is an important imaging technique that employs positronemitting radioisotopes $\left({ }^{11} \mathrm{C},{ }^{18} \mathrm{~F},{ }^{15} \mathrm{O},{ }^{13} \mathrm{~N}\right) .{ }^{9}$ It provides valuable in vivo information on biochemical mechanisms but a major challenge is the incorporation of unstable isotopes into biomolecules; ${ }^{18} \mathrm{~F}$, for example, has a half-life of 110 minutes. Hypervalent iodine derivatives, in particular diaryliodonium salts, have proved to be valuable reagents for incorporating $\left[{ }^{18} \mathrm{~F}\right]$ fluoride into aromatic molecules. This approach was first demonstrated by Pike and Aigbirhio in 
$1995,{ }^{35}$ and the method summarised in Equation 4 has proved to be a useful method for nucleophilic fluorination using $\left[{ }^{18} \mathrm{~F}\right]$-fluoride. ${ }^{36-38}$

$$
\begin{aligned}
& \stackrel{\operatorname{Ar}}{\mathrm{Ar}-\mathrm{I}^{+}} \mathrm{X}^{-} \stackrel{\left.{ }^{18} \mathrm{~F}\right] \mathrm{KF} . \text { Kryptofix-222 }}{\text { MeCN or DMSO }} \quad \mathrm{Ar}-{ }^{18} \mathrm{~F}+\mathrm{Ar}-\mathrm{I} \\
& \mathrm{F}-\mathrm{Xe}-\mathrm{F} \quad \frac{\left[{ }^{18} \mathrm{~F}\right] \mathrm{CsF} . \text { Kryptofix-222 }}{\mathrm{CH}_{2} \mathrm{Cl}_{2}}{ }^{18} \mathrm{~F}-\mathrm{Xe}-\mathrm{F}
\end{aligned}
$$

Our work on fluorodesilylation using $\mathrm{XeF}_{2}$ (Section 3.1), together with our interest in related hypervalent iodine chemistry, led to a collaboration with Pike and Aigbirhio at the MRC Cyclotron Unit (Hammersmith Hospital, London) to explore the possibility of using $\left[{ }^{18} \mathrm{~F}\right]-\mathrm{XeF}_{2}$ for electrophilic fluorination of target molecules. $\left[{ }^{18} \mathrm{~F}\right]-\mathrm{XeF}_{2}$ had previously been prepared from $\left[{ }^{18} \mathrm{~F}\right]-\mathrm{F}_{2}$ and other reactive species but these methods are experimentally difficult and it was decided to investigate the direct exchange of cyclotron-produced $\left[{ }^{18} \mathrm{~F}\right]$-fluoride with $\mathrm{XeF}_{2}$ under various conditions. It was found that in $\mathrm{CH}_{2} \mathrm{Cl}_{2}$ solution in a 'glassy carbon' vessel and using $\mathrm{Cs}^{+}$-Kryptofix-222, $\left[{ }^{18} \mathrm{~F}\right]$-fluoride exchanges with $\mathrm{XeF}_{2}$ in good radiochemical yield under mild conditions (Equation 5). ${ }^{39}$ This labelled material was used in $\mathrm{MeCN}$ solution to prepare $\left[{ }^{18} \mathrm{~F}\right]-2$ fluorocyclohexanone 60 from 1-(trimethylsilyloxy)cyclohexene $44(n=2)$ (Section 3.3) in 33\% radiochemical yield (Scheme 7). However, the formation of $\left[{ }^{18} \mathrm{~F}\right]-\mathrm{XeF}_{2}$ using this approach is very dependent on the conditions. In the light of our earlier studies, it was interesting to note that exchange did not occur in $\mathrm{MeCN}$ solution and the type of vessel and catalyst are also critical. This led Lu and Pike, now at the NIH Molecular Imaging Branch (Bethesda, USA), to make a more detailed study of the conditions that favour fluoride exchange, and vessel material, solvent, cation and temperature were all found to influence the outcome. ${ }^{40}$ At elevated temperatures $\mathrm{MeCN}$ can be used as solvent and this has led to the development of a method of producing $\left[{ }^{18} \mathrm{~F}\right]-\mathrm{XeF}_{2}$ in a microreactor on a production scale $(25 \mathrm{mCi})$. It was also demonstrated that $\left[{ }^{18} \mathrm{~F}\right]-$ $\mathrm{XeF}_{2}$ reacted with fluorene in $\mathrm{CH}_{2} \mathrm{Cl}_{2}$ solution in a glass vessel to give $\left[{ }^{18} \mathrm{~F}\right]$-fluorenes 61 (Scheme 7). These studies therefore lay a promising foundation for the use of $\left[{ }^{18} \mathrm{~F}\right]-\mathrm{XeF}_{2}$ as an electrophilic PET labelling agent for radiofluoridation that complements the use of nucleophilic $\left[{ }^{18} \mathrm{~F}\right]$-fluoride.<smiles>O=C1CCCCC1[18F]</smiles>

60

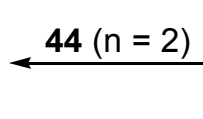

$\stackrel{\text { fluorene }}{\longrightarrow}$

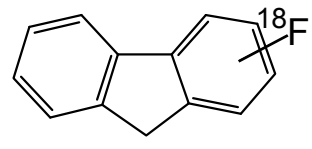

61

\section{Scheme 7}




\section{Conclusions}

$\mathrm{XeF}_{2}$ is a convenient, crystalline reagent that does not require special handling conditions. It reacts with organic molecules by two discrete mechanisms depending upon the conditions used. In the absence of an acid catalyst, reaction appears to proceed via a single-electron-transfer (SET) mechanism leading to products derived from radical cations and radicals. In the presence of a Lewis acid (LA), $\mathrm{XeF}_{2}$ reacts as a polarised reagent [ $\mathrm{FXe}^{\delta+}---\mathrm{F} \rightarrow \mathrm{LA}^{\delta-}$ ] leading to fluoroxenon intermediates $(\mathrm{R}-\mathrm{XeF})$ which readily eliminate $\mathrm{Xe}$ and fluoride to give products. We have found Pyrex glass to be a particularly effective acid catalyst for electrophilic reactions of $\mathrm{XeF}_{2}$ in solvents such as $\mathrm{CH}_{2} \mathrm{Cl}_{2}, \mathrm{CFCl}_{3}$ and $\mathrm{C}_{6} \mathrm{~F}_{6}$. However, the catalytic effect of Pyrex is inhibited when acetonitrile is used as solvent, and this is presumed to be due to the weak basicity of acetonitrile. Reaction of $\mathrm{XeF}_{2}$ with trimethylsilyl derivatives can be particularly convenient since the products TMS-F and Xe are readily eliminated and the formation of HF is avoided. The demonstration that $\left[{ }^{18} \mathrm{~F}\right]$-fluoride exchanges with $\mathrm{XeF}_{2}$ to give $\left[{ }^{18} \mathrm{~F}\right]-\mathrm{XeF}_{2}$ under mild conditions potentially provides a viable method for electrophilic $\left[{ }^{18} \mathrm{~F}\right]$-fluorination of biological ligands for positron emission tomography (PET) studies.

\section{References and Notes}

1. Ramsden, C. A. Tetrahedron 2013, 69, 4146. http://dx.doi.org/10.1016/j.tet.2013.02.081

2. Ramsden, C. A. Adv. Heterocyl. Chem. 1980, 26, 1. http://dx.doi.org/10.1016/S0065-2725(08)60139-7

3. Ramsden, C. A. Tetrahedron 1977, 33, 3193. http://dx.doi.org/10.1016/0040-4020(77)80141-5

4. Ollis, W. D.; Ramsden, C. A. Adv. Heterocycl. Chem. 1976, 19, 1. http://dx.doi.org/10.1016/S0065-2725(08)60230-5

5. Ramsden, C. A. Chem. Soc. Rev. 1994, 23, 111. http://dx.doi.org/10.1039/cs9942300111

6. Ramsden, C. A. J. Heterocyl. Chem. 1999, 36, 1573. http://dx.doi.org/10.1002/jhet.5570360618

7. Tius, M. A. Tetrahedron 1995, 51, 6605. http://dx.doi.org/10.1016/0040-4020(95)00362-C

8. Tramšek, M.; Žemva, B. Acta Chim. Slov. 2006, 53, 105.

9. PET Chemistry - The Driving Force in Molecular Imaging; Schubiger, P. A.; Lehmann, L.; Friebe, M. Eds.; Springer-Verlag: Heidelberg, 2007.

10. Huisgen, R.; Scheer, W.; Huber, H. J. Am. Chem. Soc. 1967, 89, 1753. http://dx.doi.org/10.1021/ja00983a052 
11. Katritzky, A. R.; Dennis, N. Chem. Rev. 1989, 89, 827.

http://dx.doi.org/10.1021/cr00094a006

12. Cava, M. P.; Behforouz, M.; Husbands, G. E. M.; Srinivasan, M. J. Am. Chem. Soc. 1973, 95, 2561.

http://dx.doi.org/10.1021/ja00789a025

13. Zhdankin, V. V. In Science of Synthesis, Ramsden, C. A., Ed. George Thieme Verlag KG: Stuttgart, 2007; Vol. 31a, pp 161-233.

14. Holloway, J. H. J. Fluorine Chem. 1986, 33, 149.

http://dx.doi.org/10.1016/S0022-1139(00)85275-6

15. Koser, G. F.; Wettach, R. H.; Smith, C. S. J. Org. Chem. 1980, 45, 1543. http://dx.doi.org/10.1021/jo01296a050

16. Frohn, H. J.; Klose, A.; Henkel, G. Angew. Chem. Int. Ed. Engl. 1993, 32, 99. http://dx.doi.org/10.1002/anie.199300991

17. Frohn, H. J.; Bardin, V. V. Z. Anorg. Allg. Chem. 1996, 622, 2031. http://dx.doi.org/10.1002/zaac.19966221205

18. Frohn, H. J.; Theißen, M. Angew. Chem. Int. Ed. Engl. 2000, 39, 4591. http://dx.doi.org/10.1002/1521-3773(20001215)39:24<4591::AID-ANIE4591>3.0.CO;2-8

19. Frohn, H. J.; Bardin, V. V. Organometallics 2001, 20, 4750. http://dx.doi.org/10.1021/om010490j

20. Frohn, H. J.; Theissen, M. J. Fluorine Chem. 2004, 125, 981. http://dx.doi.org/10.1016/j.jfluchem.2004.01.019

21. Bilir, V.; Bläser, D.; Boese, R.; Frohn, H. J. J. Fluorine Chem. 2009, 130, 824. http://dx.doi.org/10.1016/j.jfluchem.2009.05.010

22. Lothian, A. P.; Ramsden, C. A. Synlett 1993, 753. http://dx.doi.org/10.1055/s-1993-22596

23. Lothian, A. P.; Ramsden, C. A.; Shaw, M. M.; Smith, R. G. Tetrahedron 2011, 67, 2788. http://dx.doi.org/10.1016/j.tet.2011.02.016

24. Reprinted from Tetrahedron 67/13, A. P. Lothian, C. A. Ramsden, M. M. Shaw and R. G. Smith, Ipso-fluorination of aryltrimethylsilanes using xenon difluoride, 2788, 2011, with permission from Elsevier.

25. Ramsden, C. A.; Smith, R. G. J. Am. Chem. Soc. 1998, 120, 6842. http://dx.doi.org/10.1021/ja9804316

26. Shaw, M. M.; Smith, R. G.; Ramsden, C. A. Arkivoc 2011, (x), 221. http://dx.doi.org/10.3998/ark.5550190.0012.a18

27. Shaw, M. M.; Smith, R. G.; Ramsden, C. A. J. Fluorine Chem. 2002, 116, 71. http://dx.doi.org/10.1016/S0022-1139(02)00100-8

28. Bardin, V. V.; Frohn, H. J. J. Fluorine Chem. 1998, 90, 93. http://dx.doi.org/10.1016/S0022-1139(98)00164-X

29. Nongkunsarn, P.; Ramsden, C. A. J. Chem. Soc., Perkin Trans. 1 1996, 121. 
30. Ramsden, C. A.; Shaw, M. M. Tetrahedron Lett. 2009, 50, 3321.

http://dx.doi.org/10.1016/j.tetlet.2009.02.090

31. Patrick, T. B.; Johri, K. K.; White, D. H. J. J. Org. Chem. 1983, 48, 4158. http://dx.doi.org/10.1021/jo00170a072

32. Patrick, T. B.; Johri, K. K.; White, D. H.; Bertrand, W. S.; Mokhtar, R.; Kilbourn, M. R.; Welch, M. J. Can. J. Chem. 1986, 64, 138.

http://dx.doi.org/10.1139/v86-024

33. Patrick, T. B.; Khazaeli, S.; Nadji, S.; Hering-Smith, K.; Reif, D. J. Org. Chem. 1993, 58, 705.

http://dx.doi.org/10.1021/jo00055a026

34. Pike, V. W.; Aigbirhio, F. I. J. Chem. Soc., Chem. Commun. 1995, 2215.

35. Ramsden, C. A.; Smith, R. G. Org. Lett. 1999, 1, 1591.

http://dx.doi.org/10.1021/o1990231e

36. Cai, L.; Lu, S.; Pike, V. W. Eur. J. Org. Chem. 2008, 2853.

http://dx.doi.org/10.1002/ejoc.200800114

37. Chun, J-H.; Lu, S.; Lee, Y-S.; Pike, V. W. J. Org. Chem. 2010, 75, 3332.

http://dx.doi.org/10.1021/jo100361d

PMid:20361793 PMCid:PMC2891105

38. Yusubov, M. S.; Svitich, D. Y.; Larkina, M. S.; Zhdankin, V. V. Arkivoc 2013, (i), 364.

39. Constantinou, M.; Aigbirhio, F. I.; Smith, R. G.; Ramsden, C. A.; Pike, V. W. J. Am. Chem. Soc. 2001, 123, 1780.

http://dx.doi.org/10.1021/ja003321j

40. Lu, S.; Pike, V. W. J. Fluorine Chem. 2010, 131, 1032.

http://dx.doi.org/10.1016/j.jfluchem.2010.07.009

PMid:20871806 PMCid:PMC2944032

\section{Author's Biography}

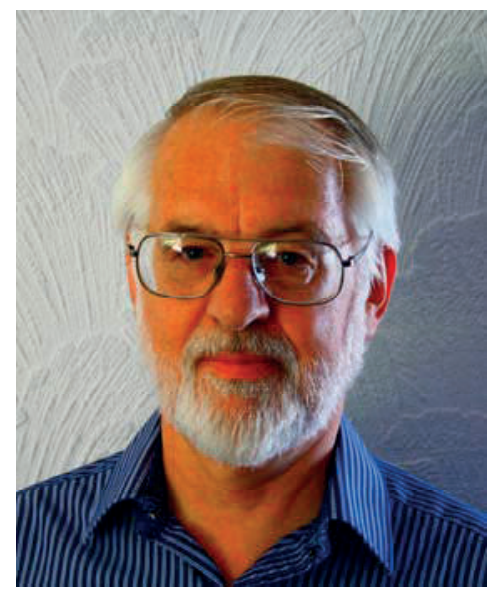


Chris Ramsden was born in Manchester, U.K. He is a graduate of Sheffield University and received his Ph.D. (W. D. Ollis) in 1970 and D.Sc. in 1990. From 1971 to 1973 he was a Robert A. Welch Post-doctoral Fellow at the University of Texas where he worked with M. J. S. Dewar on the development and application of semi-empirical molecular orbital methods. In 1973 he moved to the University of East Anglia where he was an ICI Postdoctoral Research Fellow in association with A. R. Katritzky. After a period in the pharmaceutical industry, including Head of Medicinal Chemistry (1986-1992) at Rhone-Poulenc (London), he moved to Keele University (1992) as Professor of Organic Chemistry. His current research interests include studies of mechanistic aspects of the enzyme tyrosinase and associated ortho-quinone chemistry, the structure and chemistry of heterocyclic mesomeric betaines, the synthesis of pyridine-stretched nucleoside analogues, and the chemistry of hypervalent derivatives of iodine and xenon. He is a co-author of 'The Handbook of Heterocyclic Chemistry', $3^{\text {rd }}$ Edn, 2010 and an Editor-in-Chief of 'Comprehensive Heterocyclic Chemistry III'. He has been a Scientific Editor for Arkivoc since 2000 and is a member of the Arkivoc Steering Committee. 